$\begin{array}{lllllllllllllll}\text { A C T A } & \text { C H E M I C A } & \text { S C A N D I N A V I C A } 25 & (1971) & 669-672\end{array}$

\title{
Spectral and Magnetic Properties of Complexes Formed by Copper(II) Benzoate and Copper(II) Chlorobenzoates with Some Diamines
}

\author{
MILA N MELNIK*
}

Department of Inorganic Chemistry, University of Helsinki, Helsinki 17, Finland

\begin{abstract}
Complexes of copper(II) benzoate and copper(II) chlorobenzoates with ethylenediamine, 1,2-propanediamine, and 1,3-propanediamine have been prepared. Magnetic data of the mono- and bisdiamine complexes were determined. All mono- and bisdiamine complexes are magnetically dilute. A square planar structure is assigned to the monodiamine complexes and a tetragonal structure to the bisdiamine complexes. The electronic spectra of the complexes corroborate these structures.
\end{abstract}

$\mathbf{I}_{\mathrm{b}}^{\mathrm{n}}$

1963, Koizumi et al. ${ }^{1}$ showed with X-rays that crystalline copper(II) benzoate trihydrate has a polymeric structure $\left[\mathrm{Cu} \cdot \mathrm{C}_{6} \mathrm{H}_{5} \mathrm{COO} \cdot 2 \mathrm{H}_{2} \mathrm{O}\right]_{n}$ consisting of linear chains of copper ions bridged by two water oxygen atoms and one carboxylate group. In spite of the short $\mathrm{Cu}-\mathrm{Cu}$ distance, $3.15 \AA$, the compound has a normal magnetic moment 1.87 B.M..,3

In contrast, the addition compounds formed by copper(II) benzoate with ethanol, urea, benzoic acid, ${ }^{2,3}$ benzaldehyde, ${ }^{4}$ pyridine, ${ }^{4,5}$ bipyridyl, ${ }^{5}$ butanol, ${ }^{6}$ and heterocyclic $N$-oxides are all magnetically non-dilute. The results lead to the conclusion that there exist paired copper atoms in the crystals of these complexes as in the crystals of copper(II) acetate monohydrate., ${ }^{8,9}$

On the other hand, the values 1.91 and 1.90 B.M. which have been determined for the bispyridine complex of copper (II) benzoate and its monohydrate ${ }^{4}$ indicate that these complexes probably have mononuclear structures.

Magnetic and spectral studies of copper(II) chlorobenzoates have been made by Lewis et al. ${ }^{10,11}$ Their results show that the value of the magnetic moment very often depends upon the method of preparation of the salt. In 1964, Yamada et al. ${ }^{12}$ concluded from electronic spectra that the salts have a binuclear structure. Similar structures have been proposed for

\footnotetext{
* Permanent address: Department of Inorganic and Organic Chemistry, Pharmaceutical Faculty, Komensky University, Bratislava, Czechoslovakia.
}

Acta Chem. Scand. 25 (1971) No. 2 
$\mathrm{Cu}\left(o-\mathrm{ClC}_{6} \mathrm{H}_{4} \mathrm{COO}\right)_{2} \cdot \mathrm{C}_{5} \mathrm{H}_{5} \mathrm{~N}^{10}$ and $\mathrm{Cu}\left(p-\mathrm{ClC}_{6} \mathrm{H}_{4} \mathrm{COO}\right)_{2} \cdot \mathrm{C}_{2} \mathrm{H}_{5} \mathrm{OH}{ }^{13}$ on the basis of their magnetic and spectral study.

In the present paper, the preparation of copper(II) benzoate and copper (II) chlorobenzoate complexes of ethylenediamine, 1,2-propanediamine and 1,3-propanediamine is described and the electronic absorption spectra and magnetic susceptibilities of the complexes are presented.

\section{EXPERIMENTAL}

Copper(II) benzoate trihydrate was prepared from aqueous solutions of copper sulfate and sodium benzoate by the method of Ephraim and Pfister ${ }^{14}$ Copper(II) salts of chloro-substituted benzoic acids were prepared by a similar method. The monohydrate of copper(II) o-chlorobenzoate and copper(II) $p$-chlorobenzoate, and the dihydrate of copper(II) $m$-chlorobenzoate were isolated.

The monodiamine complexes were prepared by adding a solution of a diamine in acetone to a solution containing an equimolar amount of copper(II) salt in acetone. The mixture was refluxed for a few hours and then filtered. The filtrate was concentrated under reduced pressure. The blue microcrystals that separated when the filtrate cooled to room temperature were isolated, washed with ether, and dried at room temperature.

The bisdiamine complexes were prepared by mixing the copper(II) salt with a diamine in acetone in the molar ratio of 1:2.5. Violet microcrystalline products precipitated after several minutes. The violet products were separated, washed and dried as in the case of the preceding complexes.

Copper was determined by electrolytic deposition on a platinum electrode and nitrogen by standard microanalytical procedures. Analytical data for the complexes are given in Table 1.

Magnetic measurements. Magnetic susceptibilities were determined at room temperature by the Gouy method, using equipment and procedures that have been described previously. ${ }^{15}$ Magnetic data for the complexes are given in Table 1.

Electronic spectra. Visible absorption spectra of the complexes in Nujol mulls were measured with a Beckman DK $2 \mathrm{~A}$ ratio recording spectrophotometer.

\section{RESULTS AND DISCUSSION}

As seen in Table 1, the magnetic moments of the monodiamine complexes fall in the range $1.91-1.96$ B.M. The solid spectra (in Nujol) of all the monodiamine complexes exhibit absorption bands at ca. $15860 \mathrm{~cm}^{-1}$. These results suggest that the monodiamine complexes have mononuclear structures, which obviously have approximately square planar arrangements with the acid anions as monodentate ligands in cis positions. The statement of Narain ${ }^{16}$ that bis(benzoato) ethylenediaminecopper(II) and bis(benzoato)-1,2-propanediaminecopper(II) are violet in color seems to be erroneous, for these complexes were found to be blue. The bisdiamine complexes were, however, violet.

From the standpoint of the magnetic properties of the bisdiamine complexes it is possible to classify these complexes as so-called magnetically dilute copper (II) complexes with a tetragonal distorted octahedral coordination of the copper atom. The electronic spectra of the complexes (in Nujol), which have absorption bands at $c a .18200 \mathrm{~cm}^{-1}$, corroborate this conclusion.

The bis(1,2-propanediamine)copper(II) benzoate tetrahydrate studied by Uggla et al. ${ }^{17}$ was found to have a monoclinic unit cell with space group $P 2_{1}$ or $P 2_{1} / m$. The similarity of the spectral and magnetic properties of the 
Table 1. Analytical and magnetic data for copper(II) benzoate and copper(II) monochlorobenzoate complexes of ethylenediamine (en), 1.2-propanediamine (1,2-PDA), and 1,3-propanediamine (1,3-PDA).

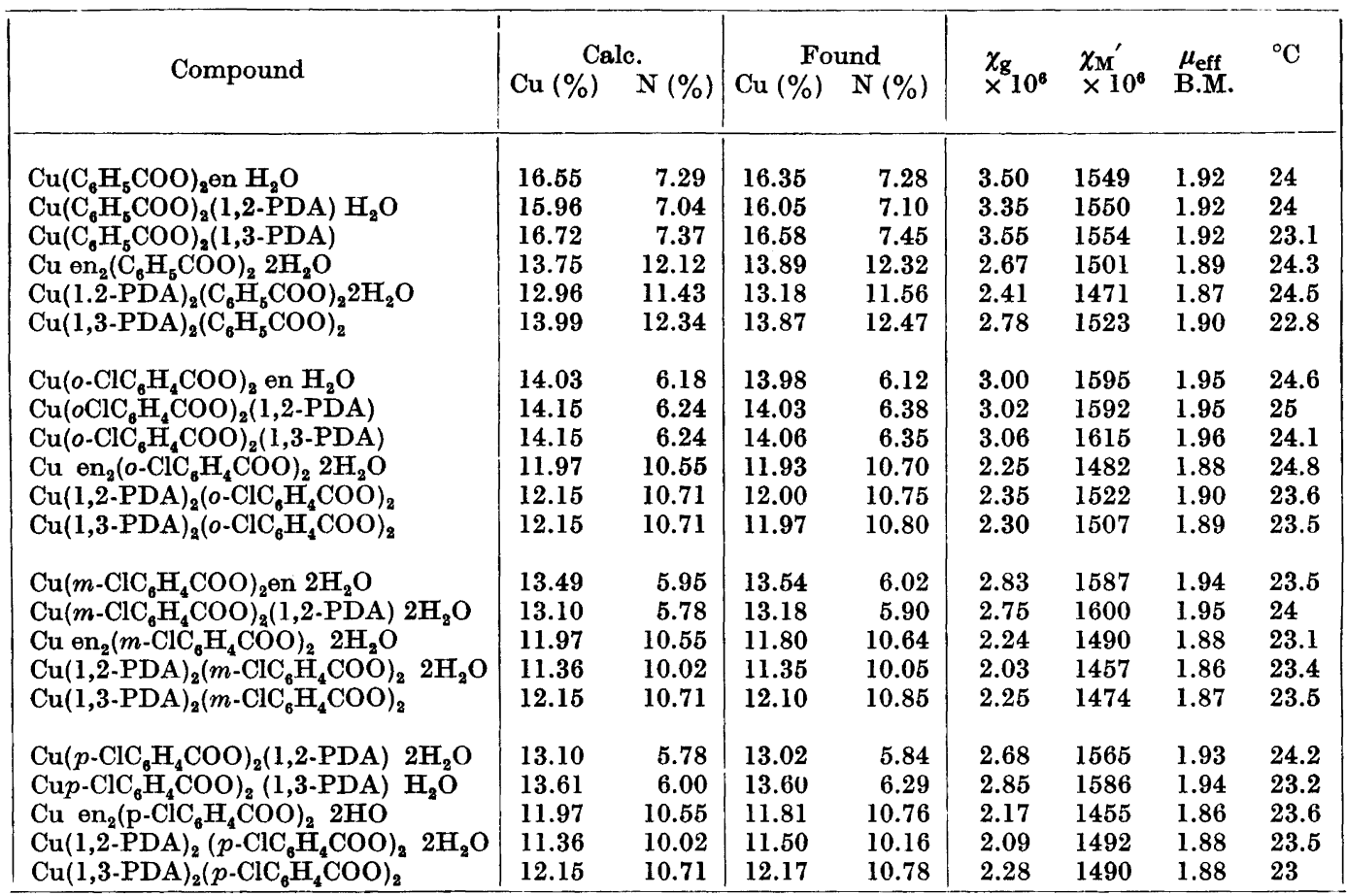

diamine complexes of copper(II) benzoates and copper(II) chlorobenzoates, and those of the complexes formed by some copper(II) alkanoates with diamines ${ }^{15,18}$ suggests that the complexes have similar mononuclear structures.

Acknowledgement. I wish to thank Professor Reino Näsänen for the interest he has shown in this work and for his valuable comments on the manuscript.

\section{REFERENCES}

1. Koizumi, H., Osaki, K. and Watanabe, T. J. Phys. Soc. Japan 18 (1963) 117.

2. Inoue, M., Kishita, M. and Kubo, M. J. Chem. Soc. Japan 84 (1963) 759.

3. Inoue, M., Kishita, M. and Kubo, M. Inorg. Chem. 3 (1964) 239.

4. Gillard, R. D., Harris, D. M. and Wilkinson, G. J. Chem. Soc. 19642838.

5. Lewis, J. and Mabbs, F. J. Chem. Soc. 19653894.

6. Hatfield, W. E., Fountain, C. S. and Whyman, R. Inorg. Chem. 5 (1966) 1855.

7. Krätsmár-Šmogrovič, J. and Melník, M. Z. Naturforsch. 24b (1969) 1479.

8. van Niekerk, J. N. and Schoening, F. R. L. Nature 171 (1953) 36.

9. van Niekerk, J. N. and Schoening, F. R. L. Acta Cryst. 6 (1953) 227.

10. Lewis, J., Lin, Y. C., Royston, L. K. and Thompson, R. C. J. Chem. Soc. 19656464.

11. Lewis, J. and Thompson, R. C. Nature 200 (1963) 468.

12. Yamada, S., Nishikawa, H. and Miki, S. Bull. Chem. Soc. Japan 37 (1964) 576.

Acta Chem. Scand. 25 (1971) No. 2 
13. Whyman, R., Hatfield, W. E. and Fountain, C. S. Inorg. Chem. Acta 1 (1967) 429.

14. Ephraim, F. and Pfister, A. Helv. Chim. Acta 8 (1925) 374.

15. Melník, M. and Näsänen, R. Suomen Kemistilehti B 42 (1969) 276.

16. Narain, G. J. prakt. Chem. 38 (1968) 362.

17. Uggla, R., Lundell, S. and Patrikka, J. Suomen Kemistilehti B 42 (1969) 269.

18. Melník, M. and Näsänen, R. Suomen Kemistilehti B 43 (1970) 99.

Received June 25, 1970. 